\title{
Teoría de la práctica lexicológica
}

\author{
José María Becerra Hiraldo \\ Universidad de Granada
}

Recibido: 13 de diciembre de 2010 / Aceptado: 8 de julio de 2011

ISSN: $1697-7467$

\begin{abstract}
RESUMEN: Exponemos un método para ejercitarnos en la práctica del vocabulario español. Se trata de un método lexicológico que intenta explotar y aprovecharse de las relaciones sistemáticas que existen entre las unidades léxicas. Para ello, siguiendo un criterio de aproximación, planteamos ejercicios de sustitución, selección, relación y asociación, así como con el criterio de enfrentamiento proponemos ejercicios de contraste, variación y transformación. Todo está refrendado por un marco teórico que justifica el conjunto de los ejercicios.
\end{abstract}

Palabras clave: Enseñanza y aprendizaje del vocabulario, Lengua española para extranjeros, Lengua española, Lexicología.

\section{Theory of lexicologic practice}

\begin{abstract}
Here we show a method to practise Spanish vocabulary. It is a lexicological method which exploits systematic relations existent among lexical units. To that purpose we suggest two different sets of exercises: one of them based on an approximation criteria (substitution, selection and association tasks) and the other grounded on differentiation (contrast, variation and transformation practice).
\end{abstract}

Keywords: Vocabulary Teaching and Learning, Spanish as a Foreign Language, Spanish Language, Lexicology.

\section{INTRODUCCIÓN}

El diccionario temático del español, propuesta que hemos presentado en varias ocasiones (Becerra 1996, 1998), se puede complementar con un "taller de vocabulario", un cuaderno donde se propone todo un repertorio de ejercicios para manejar el diccionario, para comprobar el nivel de vocabulario, para incitar al uso del diccionario (Fontanillo 1983), para incrementar el volumen léxico del hablante, en definitiva, para enseñar/aprender el vocabulario (López Morales 1986, Barbadillo 1991, Luque Durán 2000). Pero este tipo de ejercicio escolar necesita una justificación teórica en el fondo y en la forma hasta ofrecer un cuerpo organizado, es decir, un método, una teoría para esta práctica lexicológica. Los ejercicios siguientes ayudan a incrementar el vocabulario (Díaz 1978): aparece, primero, la función de la palabra; después, la finalidad pedagógica del ejercicio; en tercer lugar, su razón lingüística de ser y la figura retórica ordenadora; por último, la mecánica del ejercicio, a veces entendido como juego inteligente, con su denominación popular si la tuviera. 


\section{Tipología De Ejercicios Lexicológicos}

Para ahondar en las relaciones de las palabras del vocabulario, debemos acudir a los criterios de aproximación como la sustitución, la selección, la relación y la asociación, así como a los criterios de enfrentamiento como el contraste, la variación y la transformación.

\subsection{Ejercicio de sustitución y selección ${ }^{1}$}

Debajo de cualquier ejercicio de sustitución está la capacidad de estructurarse una lengua según el principio de interrelación. Llamamos relación paradigmática a la relación de un elemento con los otros mutuamente sustituibles; esta relación se da a todos los niveles de la lengua: fonológico, morfosintáctico y léxico (Becerra 1994). Un paradigma es una serie de elementos que pueden ocupar una misma situación, teniendo en cuenta que mutuamente pueden sustituirse y que el empleo de uno de ellos excluye el uso de todos los demás del paradigma. Están, pues, en oposición: el valor de cada elemento aparece en oposición a los demás del paradigma. Así, si digo que he obtenido un "notable", excluyo "sobresaliente, aprobado y suspenso", pues los cuatro términos pueden ocupar esa posición, forman un paradigma a nivel léxico-semántico. El paradigma constituye un conjunto cerrado o acabado en sincronía. El nivel paradigmático de una lengua es esa lengua en acto (no en potencia), opuesto a otras muchas posibilidades del sistema. Acto aquí y ahora, dentro de una determinada situación. Es un entorno locativo situacional que participa, para centrar la significación, de tal manera que adquiera un único sentido. Así, por ejemplo, si recibo un telegrama que dice: llego lunes rápido seis tarde, interpreto estos semantemas en su sentido propio gracias a esa situación señalada, es decir, un telegrama. Aquí vienen bien los ejercicios de la llamada "precisión semántica". Pueden ser ejercicios para llenar espacios en blanco y, por tanto, encajar una posibilidad entre varias dentro de una situación dada, y para alterar textos, no significados.

Elegir una palabra dentro del acervo de vocabulario propio, o dentro del grupo de palabras recordadas, o dentro de las palabras ofrecidas en un ejercicio es una práctica frecuente e importante del aprendizaje del nivel léxico de una lengua. Elegimos para algo: elegimos para cambiar palabra por palabra, elegimos para acomodar una palabra a una definición; estos ejercicios implican casación, precisión semántica, selección verbal. Otras veces la selección la hacemos de entre los varios significados de una palabra general especificados en una serie de palabras más concretas y que se acomoda mejor a frases incompletas. Es un tipo de ejercicio de precisión léxica y semántica al mismo tiempo:

\section{Elección de significados:}

¿Qué significa registrar? Buscar una cosa repetidamente o con mucha minuciosidad. Tratar de descubrir lo que hay en un país recorriéndolo. Cachear a la gente sospechosa para quitarle las armas.

\footnotetext{
${ }^{1}$ Recordemos dos de las ideas estructuradoras del diccionario, las de existencia y fuerza según los criterios de integración e intensidad.
} 


\section{Elección de palabras:}

¿Qué animal se conoce también con el nombre de «raposa»? La marmota, la zorra, la ardilla.

3. ¿Está bien empleada la palabra subrayada?

Subirán los precios petrolíferos. Ocupa un cargo prominente en el Ministerio. Pronunciará un mitin. El propio jugador nos dio la noticia.

\section{Busca el error en las siguientes frases:}

Mañana se televisa el derbi Barcelona-Madrid. Aznar detenta la presidencia del Gobierno. La policía disolvió a los manifestantes. Me siento dolorido por lo que me dijiste.

\section{5. ¿Podrías decirlo mejor?}

El alcalde actúa con despreocupación. El doctor Marañón dictó una conferencia en el Instituto. El Madrid definió en los últimos minutos. Salida de emergencia. El delantero encara al portero.

6. Las matemáticas no están de acuerdo con la lengua, ¿dónde?

El partido está en los minutos de descuento. Los hijos son hoy un dilema tremendo. Empleé una década en escribir esta novela. Asistimos a un duelo dialéctico entre los portavoces de los grupos.

\subsection{Ejercicio de relación ${ }^{2}$}

La relación cosa-palabra es una parcela importante dentro de la pedagogía de la segunda lengua. Existe una limitación, el mundo de lo concreto es el dominante en esta relación, mientras que lo abstracto queda fuera de estas posibilidades expresivas. Relacionamos cosas conocidas, vistas, experimentadas por cualquier hablante, de tipo general, o específicas de nuestro entorno cultural; debemos procurar que el alumno las relacione con una palabra determinada; como en clase difícilmente manejamos cosas, acudiremos a la imagen de las cosas para relacionarlas con las palabras (Rojo Sastre 1980). El mundo de la imagen debe entrar de lleno en la clase: la imagen móvil, la imagen fija, en distintos soportes, incluso la perfilada sobre una pizarra. Existe, además, la provocación de la palabra por parte de la imagen, la imagen sin palabras (el cine mudo) a la que debemos dotar de palabras. Podemos relacionar también sonido con cosa y para ello echamos mano de la onomatopeya, no como algo que deriva de la cosa, sino como sonido que nos recuerda y nos lleva a la cosa.

El criterio de relación comporta menor vinculación entre las partes. Los tipos de relación son los siguientes:

\footnotetext{
${ }^{2}$ Este ejercicio se basa en la idea de movimiento, una de las que estructuraban nuestro diccionario, la idea de aproximación de dos elementos; y corresponde dentro de un artículo del diccionario a la acepción transpuesta por aproximación.
} 


\section{Relación cosa-palabra. Busca palabras referidas a agua:}

Palabra relacionada con el almacenamiento del agua: $\underline{\operatorname{arca}}$, otra con la rotura de una embarcación: vía; dígame una comida que tiene de base el huevo: pasado por agua; dígame una frase en que se identifica una mala comida con el agua: a pan y agua.

8. Crucigrama de miembros de un todo; encadenados; cruces de sílabas; palabras montadas; palabras truncadas; sílabas truncadas; formación de palabras por sílabas. No se trata de casar el nombre de lo dibujado con el número de recuadros dentro de un árbol de letras, sino de casar el nombre de lo dibujado que forma parte de un campo asociativo con una estructura verbal entrecruzada; estamos relacionando cosa-estructura verbal.

Crucigrama blanco y negro referido a "viaje".

Emparrillado. Coloca en posición horizontal y en los huecos que forman un enrejado, por sílabas, palabras que se refieran a «guisos».

9. Relación palabra-número (en ella se basa el juego de cifras y letras: construir palabras a partir de un número de letras). La relación palabra-número es menos productiva pero también útil cuando queramos provocar la denominación adecuada recordando cosas aprendidas y tratando de fijar conocimientos no del todo consolidados, por ejemplo, palabras relacionadas con el número tres: trípode, triángulo, trillizo; este ejercicio puede ser abierto y enumerativo, o forzado a un crucigrama o juego de palabras reglado.

Di la palabra apropiada para:

¿Lo que está compuesto de dos elementos, unidades o guarismos? ¿Anteojo con lunetas para ambos ojos? ¿El que se casa por segunda vez, viviendo el primer cónyuge?

10. Relación situación-frase hecha, proverbio; relación no muy vinculante pero sí productiva. Di la frase que corresponda a la situación:

Suspendieron en lengua española al hijo del profesor de español. Cuando llegamos no quisieron recibirnos.

11. Relación descripción de un sonido-palabra. Di la palabra onomatopéyica para:

Gorjeo de los pájaros. Quiebro que se hace con la voz en la garganta. Lamento en el cante andaluz.

12. Jeroglífico: relación composición de imágenes-palabras, es decir, entre el dibujo y la palabra. Pictionary: identificar el nombre de los dibujos. Trazario: pintar lo designado por palabras, siguiendo el abecedario.

\subsection{Ejercicio de asociación ${ }^{3}$}

Implica más vinculación entre las partes que el criterio anterior. Es una fase posterior y más profunda que la relación. Asociamos cosas iguales o vinculadas o incluidas,

${ }^{3}$ La asociación se basa en varias ideas generales: existencia, tiempo y espacio, cantidad, lugar, orden y número, lo que la hace muy productiva pedagógicamente; y se corresponde dentro del artículo del diccionario a las acepciones por extensión, proximidad e inclusión. 
relacionamos cosas parecidas pero alejadas. Por asociación se establece relación sémica, de metonimia y de sinécdoque, entre dos lexemas distintos. En la metonimia se emplea el lexema que manifiesta un semema o semas incluidos; por una relación de causa a efecto, decimos buena pluma por escritor; de efecto a causa, decimos las canas por la vejez; de signo a significado, decimos el laurel por la gloria. Para sacar provecho de esta posibilidad de la lengua, podemos hacer ejercicios de casación y de estimulación, teniendo en cuenta la dificultad del mismo dado su componente connotativo y metafórico.

Asociación por metonimia. La metonimia implica que el significado de los lexemas distintos están incluidos entre sí, es decir, que casi todos los semas de uno aparecen en el otro (no hay escritor sin pluma, pero sí hay pluma sin escritor). Lo mismo se puede decir de la sinécdoque. Algo distinto ocurre en la intersección de dos o más lexemas que tienen un sema común, por ejemplo, barco-tren, cuyos sememas ofrecen como común el sema 'medio de transporte'. Esta afinidad sémica es la base para organizar la parte analógica del diccionario ideológico y los campos asociativos; el diccionario ideológico ofrece grupos de palabras afines, encabezados por sustantivos, grupos de diversa índole, simples o sencillos, compuestos, con una estructura interna coherente (se separan las categorías y dentro de ellas se aplican las analogías u ordenaciones por semejanzas), y con unas ramificaciones laterales enriquecedoras sin perder la idea rectora y el punto de partida; esta parte analógica nos permite confeccionar ejercicios de asociación, agrupación, de estimulación, de precisión léxico-semántica, etc.

El campo asociativo engloba en cierta forma el fenómeno de la heteronimia, es decir, engloba vocablos de acusada proximidad semántica que proceden de étimos diferentes, por ejemplo, toro-vaca (Calero Heras 1992, Moreno Cabrera 2004); por la hiponimia se establece una relación especial entre un lexema específico y otro más general (vaca) animal); la relación inversa se llama hiperonimia; la hiponimia puede definirse mediante la implicación unilateral no simétrica, mientras que la sinonimia lo hace mediante la hiponimia bilateral o simétrica; la hiponimia es una relación transitiva (vaca-mamífero, mamífero-animal, vaca-animal); la adquisición del lenguaje ha sido propiciada por los razonamientos hiponímicos (¿Qué clase de animal es? Una vaca); la hiponimia es una relación paradigmática de sentido que se funda en la encapsulación en el hipónimo de alguna modificación sintagmática en el sentido del lexema hiperónimo (tirano>gobernante despótico, elefante>animal grande).

La elaboración de conjuntos de muchos miembros léxicos (elementos químicos, especies botánicas) es más típica de taxonomías especializadas y rígidas que de la lengua general; dentro de esta lengua la relación de sentido en un conjunto de muchos miembros se denomina "incompatibilidad" (Esto es una rosa, no un clavel), y se basa en un contraste dentro de la similitud. Los conjuntos de muchos miembros incompatibles se ordenan:

a. Por series, en que aparecen los lexemas extremos y los demás quedan ordenados entre los dos; hay que distinguir las escalas, de lexemas graduables, que son series variables (óptimo-bueno...pésimo) porque admiten más lexemas, hay pares (bueno/malo), hay equivalentes (óptimo=muy bueno); y los rangos, o lexemas seriados de manera estricta, (vocabulario técnico), términos incompatibles y no graduables (calificaciones, numerales, rangos militares);

b. Por ciclos, en que aparecen los lexemas en términos de sucesión (estaciones, meses, días de la semana), sin miembros extremos. 
Dentro de los campos asociativos, la analogía se puede establecer:

\section{Por vecindad fonética ${ }^{4}$.}

Busca palabras distintas de igual o parecido sonido:

Voy a contraer matrimonio: me caso; voy a matar animales: cazo.

Disparo la escopeta: tiro; árbol que produce hojas para infusión: tilo.

Escribe una o dos palabras españolas parecidas a esta: acechar, diferencia, roja, tejo, espaldilla.

14. Trabalenguas. Palabra o locución difícil de pronunciar, en especial cuando sirve de juego para hacer que alguien se equivoque.

Scattergory: recordar palabras, dadas letras del abecedario.

15. Asocie uno de los siguientes significados (Neggers 1975):

Abismo. Cumbre (sima). Acción de abrir. Inauguración (apertura).

16. Paronimia. Asocie una de las palabras:

Adversión o aversión 'antipatía o repugnancia exageradas hacia algo'. armario o almario 'mueble con puertas que sirve para guardar ropa'.

17. Casación por vecindad léxica. Las siguientes palabras tienen una configuración rara. Arréglalas: metereología, pograma, portaviones, Uropa, córpore in sepulcro.

18. Casación por vecindad gramatical. En las siguientes construcciones comunes pon un verbo adecuado: dar una fecha, echar una película, echar un discurso, ponerse de rodillas, haber un gran silencio.

19. Casación por vecindad física o de contexto mediante ejercicios de observación, selección y asociación ${ }^{5}$.

Nombre 20 objetos de una cocina. Nombre diez objetos que puedes encontrar en la clase.

${ }^{4}$ En la base de este fenómeno está la homonimia o relación sémica entre lexemas idénticos; esta relación puede ser de independencia de los semas de los sememas (gato 'animal doméstico', 'herramienta'), y, en cuanto a la forma, lexical o total si ofrecen idéntica categoría gramatical (turba), gramatical, si son de distinta categoría (vino), léxico-gramatical los formados por conversión categorial (querer: verbo>sustantivo). Es preciso hablar también de la homofonía, o palabras homónimas de igual sonido, y de la homografía, palabras homónimas de igual sonido y grafía. En resumen, hay que hablar de la paronimia que se da en las palabras semejantes entre sí por su etimología o por su forma o sonido.

5 El método Assimil en sus veinte primeras lecciones recoge los siguientes contextos como ambientes más comunes donde se utilizan palabras asociadas entre sí: la familia, las relaciones sociales, casa, barrio, en el teléfono, en el juego, en el bar, en el campo, en la tienda, pedir dinero, comprar un coche. Los ejercicios apropiados para explotar esta característica funcional del vocabulario son los de invención, casación y derivación. Cfr. (Margosein 1982, Karbon 1984, Heimlich 1990, Hallen 1994). 
20. Por vecindad semántica. Se trata de una agrupación de palabras de significado vecino:

Asocie una de las definiciones: teleobjetivo: objeto que permite tomar fotos a distancia, aparato para medir la distancia a que se encuentra un objeto, pez del superorden de los teleósteos.

Localización: sopa de letras, relacionar palabras con significado.

Relación entre tres palabras para una definición y lo definido (trivial pursuit, global trivial: dadas tres palabras para una definición, dar con la verdadera).

Preguntar sobre las palabras, sobre sus significados; relacionar nombre con descripción, significados con palabras.

Ingeniario: juego alocado de definiciones.

\section{Busca el rango}

¿Oficial inmediatamente superior al teniente? ¿Superior del profesor titular de universidad? ¿Grado superior al cura párroco? ¿Clase social acomodada?

22. Busca el género próximo.

De falda, de facistol, de falange, de cierzo, de churumbel.

23. Busca el nombre de los conjuntos.

¿Agrupación de animales pequeños que viven juntos? ¿Una porción de ganado? ¿Conjunto de hormigas que habitan en un mismo nido?

24. Busca el nombre de los miembros de un conjunto.

Diez nombres de 'especies de ave': águila, carpeta, papagayo, rueda, tórtola, golondrina, pollo, urogallo, cóndor, urraca, jilguero, avestruz, paloma, canguro, alondra.

25. Busca el nombre de los miembros de una escala.

Para valorar una cosa en su justa medida me encuentro entre dos extremos: valor/ demérito; partiendo del extremo 'valor', di diez adjetivos que gradualmente lleven al extremo 'demérito'.

Para expresar la oposición calor/frio, di trece adjetivos que expresen gradualmente el paso de una situación a otra.

26. Busca el nombre de los miembros de un ciclo.

Los momentos del día, el nombre de las comidas (por orden), los períodos de la vida de una persona.

27. Busca el nombre de los términos de un rango.

Las calificaciones de un examen (de menos a más), las operaciones con el número tres, los miembros del rango militar, empresarial, educativo y clerical (de más a menos).

28. Derivación. Asociar palabra primitiva con derivada; (separar prefijos, formar otras dados prefijos, asociación prefijos con palabras, prefijos con significados, separación de sufijos, asociación sufijo-palabra, formación de diminutivos y aumentativos). 
Distinción: sufijos que indican oficio, sufijos para gentilicios.

Familias de palabras. Clasificación por significado, búsqueda de familias (Maldonado 1998).

Asociación palabra primitiva-palabra derivada:

Di la palabra derivada de comida: Comida variada y muy abundante, complacencia especial que uno tiene en cosas de su inclinación.

29. Asociación continente-contenido. Completa las frases:

La corre por las venas. Tanto va el a la fuente, que se rompe. Vamos como sardinas en. En la calle había un embotellamiento de coches.

30. Asociación instrumento-instrumentista. Unir los nombres de dos listas, una de instrumentos y otra de instrumentistas.

31. Asociación simbolo-simbolizado. Completa la frase:

Quería conseguir una en la carrera. Siempre lleva en la solapa la insignia de la asociación. Los toros llevan la en el morrillo.

\section{Asociación abstracto-concreto.}

De las diez palabras siguientes, cinco son abstractas y cinco concretas. Agrúpalas: apetito, interés, contrato, alejamiento, piel, sueños, hada, acto, luz, haber.

\section{Asociación general-particular.}

De las diez palabras siguientes, 5 son generales y 5 particulares. Agrúpalas: embarcación, guateque, gráfico, cordón, bolsa, cante, cocinar, traductor, guerra, junta.

Separar prefijos, formar otras dados prefijos, asociación prefijos con palabras, prefijos con significados, separación de sufijos, asociación sufijo-palabra, formación de diminutivos y aumentativos, distinción, sufijos que indican oficio, sufijos para gentilicios.

Asociación por sinécdoque. Es otro tipo de asociación semántica, también dentro del fenómeno de la inclusión, por la que extendemos, restringimos o alteramos de algún modo la significación de las palabras para designar un todo con el nombre de alguna de sus partes; o al revés, un género con el de una especie, o al revés, una cosa con el de la materia que está formada (velas por naves, pan por todo alimento, bronce por campana). Se trata de una relación sémica entre lexemas distintos en inclusión. Esta relación sémica se manifiesta en A) relaciones parte-todo: de las que existen diversos tipos y no hay acuerdo en si es transitiva (puño-manga-chaqueta); son muy claras en nombres que denotan objetos físicos discretos (rueda-bicicleta; lente-parte de una cámara), en nombres colectivos (ganado, mobiliario) que permiten ejercicios de encadenamiento. B) la estructura jerárquica del vocabulario, que permite delinear un diagrama arbóreo en el que partiendo de un nombre genérico aparece un hipónimo inmediato y otro mediato (animal: pájaro, pez). Existen serias dificultades para llevar a la práctica en las lenguas este principio. El diccionario ideológico, en parte, lo resuelve porque ofrece, en su parte sinóptica, un plan general de clasificación ideológica, que va de Dios a las últimas instituciones sociales en desdoblamientos descendentes; y, además, ofrece 38 cuadros sinópticos o grupos de vocablos homogéneos distribuidos por clases, que cuando son 
abstractas permiten los antónimos. C) los vacíos léxicos, que existen cuando no aparece lexema hiperónimo en una pareja de cohipónimos (profesor/alumno), o cuando no encontramos hipónimos de un hiperónimo existente (hondo/0/). D) los pares de términos (marcado/no marcado); la marcación, o su ausencia, se basa en la presencia o ausencia de algún determinado elemento en la forma (león/leona) de dos lexemas complementarios; el marcado es distribucionalmente más restringido; la marcación permite la diferenciación sexual, que es la más sencilla y evidente.

Esta relación sémica es la base del llamado "análisis componencial" de Pottier y Coseriu (Coseriu 1966), análisis que no tiene gran utilidad para el aprendizaje de segundas lenguas pero permite profundizar en el conocimiento de la lengua materna.

Las técnicas de ejercitación (algunas mencionadas por Ch. Bally) (Durrer 1998) que se basan en el criterio de "asociación" y que estimulan la figura de la sinécdoque son:

34. Halla el nombre de las partes de un todo:

¿De cuántas partes se compone una bicicleta? Decir ocho. ¿De cuántas partes se compone un traje? Decir tres.

Completa el nombre de «novela» con 12 complementos que indiquen sus 'tipos': aventuras, científica, policíaca,...

Completa la frase, en la que se omite o el nombre principal o el apuesto:

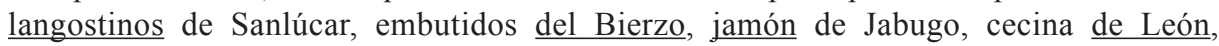
queso manchego, morcilla de Burgos.

35. Halla los pares marcados:

Di el nombre de la hembra del león, tigre, camello, elefante, perro, águila, avestruz, pollo, gallo.

36. Halla la materia de un objeto:

¿De qué materia está hecho el libro, la mesa, el lápiz, la carretera, el espejo, la playa?

Di 12 cosas 'hechas con tela'.

37. Halla el sujeto de una acción:

dirigir un partido de fútbol, rumiar, tiritar, construir casas, dirigir el tráfico de una ciudad.

38. Halla el resultado de una acción:

de llover, de correr, de comer, de dormir, de hablar.

39. Halla el 'producto' de algo o su 'productor':

de la encina y el roble, de la caña de azúcar, de algunas palmeras, del olivo, de la vid.

40. Halla la utilidad de una acción:

¿Para qué estudiamos? ¿Para qué trabajamos? ¿Para qué rezamos a Dios? ¿Para qué echamos el ancla de una nave? 


\section{Halla el lugar donde se desarrolla una acción:}

¿Dónde se proyecta una película? ¿Dónde están los cerdos? ¿Dónde recibimos el baño de vapor? ¿Dónde trabaja el que afeita barbas? ¿Dónde se visten los actores para salir a escena?

42. Redundancias. Aquí sobra alguna palabra. ¿Cuál? extremo.

Accidente fortuito. Arrecirse de frío. Asomarse al exterior. Bajar abajo. Caso muy

43. Palabras compuestas. Ejercicios de formación, descomposición, formulación a partir de definición, clasificación por significados.

44. Le faltan vocales: orfndd, rdinarment, opscl, ncumplr, indcenca, dscard, cajda, cadro, benficinca, aprte, porrear, infdeldad, hbil.

45. Le faltan consonantes: excusivo, enlaquecio, chaar, beaa, desreciale, pora, quiebo, maaro, foogafía, irmar, omer, audició, cosejeo, liere, pior.

46. Completa el texto de esta receta con las siguientes palabras: derretida, manteca, haga, sartén, crujientes, chacinas, plato, fuego:

En una amplia, dore a , lento los trozos de lomo con la que lleven. Dé vueltas a la carne para que se por los dos lados sin que se reseque demasiado. Retirar. En esta misma sartén, con la manteca muy caliente, freímos al gusto las , consiguiéndose un punto mejor si se quedan por fuera y blandas por dentro. Servir todo junto en un de barro, pues queda muy típico.

47. Rompecabezas o puzzle (Sánchez Lobato 1992). Completa las frases siguientes:

Despedirse a la francesa. Despacito y buena letra. Dar un vuelco el corazón. Compuesta y sin novio. Cargar con el muerto / mochuelo / sambenito.

48. Entresaca diez frases de los siguientes fragmentos:

Censura, moción de, globo, franca, sonda, mejoría, insepulto, través, córpore, a campo, paro, en cuestión, cardíaco, poner, alto, el fuego por el mango, tener la sartén, la iniciativa, tomar.

\section{Entresaca diez locuciones de los siguientes fragmentos:}

Los pantalones, bajarse, como una ostra, aburrirse, callando, a la chita, pelado, a grito, por tres, a cada dos, las tornas, cambiar, de castidad, cinturón, artificiales, castillo de fuegos, cantar, las cuarenta, a alguien, por las hojas, el rábano, coger.

\section{Entresaca diez proverbios de los siguientes fragmentos:}

Que un gato, de escayola, ver menos, en un vaso de agua, ahogarse, la tostada, descubrir, como para, parar un tren, ir por, lana, salir trasquilado, tener más frío, que siete viejas, en la manga, guardar un as, de todo, hay, en la viña, del Señor, más tonto que, Abundio, no tener, donde caerse, muerto. 
51. Palabras sincopadas. Forma diez palabras con un grupo de segmentaciones.

52. Di el nombre de las dos caras de algunos elementos:

En la cabeza. En la mano. En las monedas. En las personas. En las hojas.

\subsection{Ejercicio de contraste $^{6}$}

Contraste en homosemia. Corresponde al fenómeno de la identidad, por el que dos conjuntos de semas exactamente iguales se manifiestan a través de dos lexemas distintos. Se parece a la sinonimia, pero mientras la sinonimia es un fenómeno discutido, la homosemia es aceptada por la carga histórica que hay detrás de cada palabra (Otaola 2004). La homosemia se manifiesta en ejercicios de sustitución de paradigmas y de identificación de significados:

53. Construcción equivalente o diferencias gramaticales:

Di de forma distinta «pasado mañana», «ahora», «delante», «dentro», «porque».

\section{Diferencias diatópicas.}

¿Cómo llaman los andaluces a la «bayeta»? ¿Cómo llaman los canarios al autobús de servicio público? ¿Cómo llaman los americanos a los «sellos»? ¿Cómo llaman al «pene»? ¿Cómo llaman a la «acera»?

\section{Diferencias diafásicas:}

¿Cómo se dice vulgarmente «gratis»? ¿Cómo le llaman los cultos al «cigarro»? Diga en culto «echar un polvo». Diga en vulgar «paseo». A una persona de vida irregular, ¿los americanos la llaman pingajo, pendón o pendejo?

\section{Diferencias diatécnicas:}

¿Cómo se dice técnicamente «dentista»? ¿Al que estudia los fenómenos del tiempo atmosférico? ¿Cómo se llama la figura retórica de aplicar cualidades humanas a cosas inanimadas?

57. Diferencias culturales: uso del tabú:

¿Cómo se le llama a la «culebra»?

58. Diferencias diastráticas: uso del eufemismo:

¿Cómo se le dice al «retrete», a la «mierda», «cagar», a la 'acción de mear', “pene”?:

Contraste en sinonimia. El ejercicio de sinónimos pretende desarrollar la habilidad de buscar la palabra que exprese en su matiz preciso una idea, huyendo de vagas

${ }^{6}$ Se sustenta en la primera idea general, la idea de la relación, es decir, la mayor o menor referencialidad; y en las ideas de cambio y causalidad, es decir, la mayor o menor duración; y se corresponde dentro del artículo del diccionario con las acepciones figurada, en el primer caso, y anticuada, en el segundo. 
aproximaciones o generalidades. Esta habilidad evita la mayoría de los problemas orales y escritos y entrena en el hábito de la variación de formular nuestros pensamientos. La sinonimia o procedimiento de afinidad semántica y la antonimia o de significación contrastante ayudan al aprendizaje del vocabulario y contribuyen a crear lo que se ha denominado "sentido de la propiedad idiomática". La sinonimia se desarrolla mediante:

59. Asociación de palabras ofrecidas dos listas.

60. Eliminación de términos no sinonímicos en grupos de palabras sinónimas (Baylon 1994): desvelo, preocupación, obsesión, hombrada, desunión, abandono.

61. Identifica series o parejas de sinónimos (guerra de palabras: identificar la construcción de palabras entrecruzadas de otro):

Une de dos en dos las siguientes palabras por su similitud: calendario, carga, almanaque, adversario, cargo, enemigo, hoya, huelga, cierre, hoyo, lentes, perjuicio, gafas, daño.

62. Sustitución en texto de palabras por sus sinónimos (García Hoz 1977, Giménez Martín 1994).

63. Enriquecimiento de un texto repetitivo con sinónimos.

Cambiar las palabras repetidas del texto.

64. Selección del sinónimo apropiado para un contexto dado:

Antes sentaban una chica sobre el coche bien bruñido, relampagueante; y lo vendían.

65. Sustitución de términos generales por particulares:

Di un término particular del genérico:

Tumor maligno. Canto andaluz. Bailarín en el cante flamenco. Bolsa que utilizan las mujeres para vestir. Fundamento de un edificio.

66. Abstractos por concretos. Di un término figurado por el real:

Abertura. Acto. Alojamiento. Apetito. Bautizo.

67. Construcción de palabras cruzadas (scrabble o crucigrama). Crucigrama de sinónimos.

68. Construcción de frases cruzadas. Di dónde hay cruce y cuál es la palabra correcta:

Solo nos acordamos de Santa Bárbara cuando nieva. Sacar a alguien de sus cosillas. Saber de qué bolsillo cojea una persona. Más fuerte que un róver. Lo limpiado por lo servido. 
69. Construcción de palabras cruzadas en tres dimensiones:

Las siguientes palabras (hablar, coger, cabeza, cielo, casa) insertadas en una frase permiten cambiar palabras y transformar las frases.

Di cinco resultados distintos de cada una de ellas.

Contraste en antonimia. Es el fenómeno opuesto a la sinonimia, aunque también se trata de una relación sémica entre lexemas distintos; esta relación llega a la intersección de significados. El contraste semántico de un término refuerza la comprensión de éste por estar en su misma línea de contenido, aunque en posición polar. No existen conceptos por sí solos, sino binomio de conceptos. La antonimia abarca a sustantivos, adjetivos, verbos y adverbios. Ha de tenerse en cuenta que no hay muchos antónimos, aunque lo parezcan (hombre/mujer), sino más bien son parejas cuyo conocimiento puede resultar útil al alumno. Los ejercicios pueden consistir en:

70. Elección entre varias posibilidades:

¿Cuál es lo contrario de «listo»? Idiota, menso, sonso. ¿Lo contrario de «paisano»? Civil, uniformado, labriego. ¿Lo contrario de «diáspora»? Recogimiento, ensimismamiento, concentración.

71. Estimulación de antónimos en palabras dadas. Di de lo contrario de:

Comer. Limpieza. Cobarde. Misántropo. Escabroso.

72. Sustitución de palabras por antónimos.

73. Decir doce antónimos de 'desorden'.

74. Asociación de pares, designación de antónimos, creación de oraciones.

Contraste en polisemia. La polisemia es un fenómeno de intersección de significados por el que entre los lexemas idénticos se establece una relación sémica. Este fenómeno es importante para la economía lingüística. Al alumno hay que hacerle comprender el cambio de significado de una palabra por intervención de los sentimientos, por metáforas, por especialización, generalización, ennoblecimiento, envilecimiento, etc. La polisemia da lugar a que en muchas palabras hay una significación primaria y otra u otras derivadas y aun figuradas. La polisemia puede producir ambigüedad. Los ejercicios más frecuentes de polisemia son:

75. Precisión semántica y observación de matices sémicos en una palabra. ¿Qué significa la palabra «casa» en las siguientes formas complejas?

Casa de labranza. Casa de huéspedes. Casa de familia. Casa de Borbón.Casa consistorial.

76. Elaboración de oraciones con los significados de «ojo»:

Ojo derecho. Ojo de la aguja. Los ojos de las tijeras. Ojo de la cerradura. Los ojos del queso 
77. Di nueve significados de la palabra aguja.

78. Búsqueda de palabras. ¿Qué palabra polisémica falta en estas oraciones?

Llevaba una bufanda alrededor del cuello. En invierno llevo jersey de alto. Habla para el de la camisa. El del jarrón estaba muy decorado.

79. Selección de significados. ¿Qué significa pata/o en las siguientes frases?:

La pata se domestica con facilidad. Siempre pago yo el pato.

80. Palabras polisémicas por cambio de categoría. Averigua la categoría.

A Marta le dio un pronto y se marchó. Ven pronto para que nos dé tiempo. No entiendo por qué ha cometido tamaño disparate. Perro de tamaño mediano. Habló ante mil personas.

Creación de frases con palabras, asociación de dibujos designados por palabras.

\subsection{Ejercicio de variación ${ }^{7}$}

81. Usa palabras distintas según las regiones para decir «mitad café-mitad leche»; para decir «mas leche que café»; «mas café que leche»; para decir "acera"; para decir "azafata".

\subsection{Ejercicio de transformación ${ }^{8}$}

Tanto los ejercicios de composición como los de derivación ayudan a comprender matices de significación más precisos y contribuyen a desarrollar las capacidades de análisis y síntesis del alumno. Estos ejercicios abarcan las siguientes actividades:

A) la lexemación, o poner lexemas verbales a los sufijos en "-izar, -icar, -ificar, -ear, -ecer"; asimismo, poner lexemas adjetivales, adverbiales, gentilicios con la ayuda de determinados sufijos.

B) la sufijación, que aporta distintos matices de significación según la palabra de que forme parte; los sufijos pueden ser apreciativos, que no modifican esencialmente el significado de la palabra a la que se unen, y significativos, que modifican el significado; entre los apreciativos están los diminutivos, los aumentativos y despectivos; los significativos pueden indicar cualidad (-anza), acción (-aje), oficio (-ero), lugar (-adero).

La transformación a partir de la palabra es un paso más en este ejercicio; se basa en el poder generativo del lenguaje y en la idea clave de contexto para poder operar; la transformación oracional se puede hacer a partir de una palabra obligatoria, o puede ser una transformación libre oracional a partir de un significado o para significar una idea. Debemos tener en cuenta la tendencia sintagmática de la lengua a fijar o encapsular

7 Tiene que ver con las ideas de tiempo y espacio; y se corresponde dentro del artículo del diccionario con la acepción de extensión.

${ }^{8}$ Se relaciona con la idea de actividad; y se corresponde dentro del artículo del diccionario con la acepción familiar, técnica, especial, según el criterio de funcionamiento. 
estructuras (se lame con la lengua; el perro ladra) lo que es restringir la capacidad productiva, pero que no es tendencia general (se puede decir buen hombre u hombre bueno); es un fenómeno de gramaticalización al que acceden los hablantes de nivel avanzado, mientras que en los niveles iniciales todavía se procede por especialización en la adquisición del lenguaje, de lo general a lo particular (primero se aprende caballo, después caballón, después caballete).

Los ejercicios recomendados en este apartado son:

82. Transformación de sentido (Becerra 1997). En sentido figurado, di pan referido a lo que se bendice en la misa: hostia, referido a los regalos de los novios: pan de la boda, referido a una persona agradecida: pan agradecido.

83. Siguiendo con este sentido, formula una frase hecha en que se muestre el desinterés amoroso: contigo pan y cebolla, en que se demuestre amistad: no haber pan partido, para indicar la falta de dificultades: ser pan comido.

84. Para denominar clases de pan, extendemos el significado 'pan' a otras palabras: si somos confiteros haremos pan de higo; si somos decoradores, utilizaremos pan de oro; si somos constructores hacemos pan de cemento.

85. Composición. Forma una palabra para decir 'técnica de cultivo de la vid'; 'falta de cultivo o de cultura'; 'técnica del cultivo de la tierra'; 'técnica de criar abejas'; 'técnica para cultivar huertos'.

86. Derivación. Forma una palabra a semejanza de cubata para decir (González 1984): un bocadillo, un socialista, una persona que consume drogas, un tocadiscos, un jubilado.

Forma una palabra a semejanza de vacile para decir:

Estado producido por el efecto de una droga. Desorden, alboroto. Robo. Inyección de droga. Trabajo.

Forma palabras con el sufijo -azo para decir:

Premio extraordinario de la lotería de la ONCE. Enriquecimiento rápido mediante especulación. Hombre que se deja dominar fácilmente por su mujer.

87. Transformación de palabras en oraciones usando claves, transformación de enunciados de un texto.

\section{REFERENCIAS BIBLIOGRÁFICAS}

Alvar Ezquerra, M. (2003). La enseñanza del léxico y el uso del diccionario. Madrid: Arco/Libros. Atkins, B.T. S., "Monolingual and bilingual learners' dictionaries: a comparison", in R. Ilson (ed.) Dictionaries, Lexicography and Language Learning. Oxford: Pergamon Press; Hemel Hempstead: Phoenix ELT, 1985, 15-24.

Ávila Muñoz, A., "La enseñanza del español basada en un corpus de lengua hablada", en J. M. BECERRA, et alii, edits., 1999, La enseñanza de segundas lenguas, Granada, GILA, págs. 107-115. 
Barbadillo de la Fuente, м. т. (1991). La enseñanza del vocabulario. Madrid: Universidad Complutense. Battenburg, J.D. (1991). English Monolingual Learners' Dictionaries. A User-oriented Study. Tübingen: M. Niemeyer.

Beattie, N., "Teaching dictionary use", Modern Languages 54: 161-168, 1993.

Becerra Hiraldo, José María, «En la enseñanza del español como segunda lengua, semántica y vocabulario», en Actas del Segundo Congreso Nacional de ASELE, Málaga, 1994, págs. 313-323.

Becerra Hiraldo, José María, "Diccionario temático del español. Propuesta”, Español actual, 65/ 1996. Madrid: Arco/Libros, S.L., 1998, págs. 5-23.

Blanco, Carmen (2005). Diversidad léxica del español y destrezas del profesor de E/LE. Pamplona: EUNSA.

Boulicaut, M. (1981). Découvrons le dictionnaire. Paris: Larousse.

Bustos Tovar, J. J. y otros (1989). Vocabulario básico en la E. G. B., Madrid. Ministerio de Educación y Ciencia: Espasa Calpe.

Calero Heras, J. (1992). Entre palabras. Para aprender a manejar el diccionario. Barcelona: Octaedro.

Carter, R. / Mac Carthy, M. / Channell, J. (1988). Vocabulary and language teaching. London: Longman.

Cervero, $\mathrm{M}^{\mathrm{a}}$ Jesús y Francisca Pichardo (2000). Aprender y enseñar vocabulario. Madrid: Edelsa.

Coseriu, E., «Structure lexicale et enseignement du vocabulaire», en Actes du I Colloque International de Linguistique Appliquée, Nancy, 1966, págs. 175-217.

Cowie, A.P. (ed.), The Dictionary and the Language Learner. Tübingen: M. Niemeyer, 1987.

Diab, T. (1990). Pedagogical Lexicography: A Case Study of Arab Nurses as Dictionary Users. Tübingen: M. Niemeyer.

Díaz Castañón, c. y otros, Vocabulario básico del Español y sus aplicaciones a la enseñanza I, ICE, Universidad de Oviedo, 1977; 1978, II.

Fontanillo, E. (1983). Cómo utilizar los diccionarios. Madrid: Anaya.

Gallart, E. y otros (1995). Juguemos con el diccionario. Barcelona: Larousse.

García Hoz, v. (1977). Estudios experimentales sobre el vocabulario. Madrid: Instituto de Pedagogía «San José de Calasanz».

Giménez Martín, M. C. y Velilla Barquero, R. (1994). Cuadernos de ejercicios gramaticales. 4. Léxico-semántico. Barcelona: Edunsa.

González Guzmán, Pascual, coord., (1984). Actas del IV Simposio de lengua y literatura para profesores de bachillerato. Granada.

Guerrero Ruiz, P. y A. López Valero (1993). Vocabulario básico para la educación infantil. Madrid: Bruño.

Hallen, W. ,ed. (1994). The World in a List of Words. Tübingen: M. Niemeyer.

Hartmann, R.R.K., "Bilingualised versions of learners' dictionaries", Fremdsprachen Lehren und Lernen, 1994, 23: 206-17.

Hartmann, R.R.K., "Pedagogical lexicography: Some desiderata", in R. Dirven and J. Vanparys (eds.) Current Approaches to the Lexicon. Frankfurt, Lang, 1995, 405-11.

Hartmann, R.R.K., "The dictionary as an aid to foreign-language teaching", in F.J. Hausmann et al. (eds.) Wörterbucher/ Dictionaries/ Dictionnaires. An International Encyclopedia of Lexicography, Berlin, W. de Gruyter, 1989, Vol. I: 181-9.

Heimlich, J. E. / Pittelman, S. D. (1990). Los mapas semánticos. Estrategias de aplicación en el aula. Madrid: Visor.

Higueras, M. (2004): “Claves prácticas para la enseñanza del léxico”, Carabela 56, 5-25. 
Howatt, A.P.R. (1984). A History of English Language Teaching. Oxford: Oxford University Press. Instituto Cervantes, Plan curricular del Instituto Cervantes. Madrid: Instituto Cervantes/Biblioteca Nueva, 2006.

Johnson, D.D. y Pearson, P.D. (1984). Teaching reading vocabulary. New York: Holt.

Justicia Justicia, F. (1985). El vocabulario usual del niño en el ciclo inicial y el ciclo medio de la E.G.B. Granada: Universidad de Granada.

Karbon, J.c. (1984). An investigation of the relationship between prior knowledge and vocabulary development using semantic mapping with culturally diverse students. University of Wisconsin: Madison.

López Morales, H. (1986). La enseñanza de la lengua materna. Madrid: Playor.

Luque Durán, Juan de Dios y Francisco José Manjón Pozas, coords., Segundas jornadas sobre el estudio y la enseñanza del léxico. Método Ediciones, 1996. (Otras actas en 1997, 1998, 1999, 2000).

Maldonado González, C. (1998). El uso del diccionario en el aula. Madrid: Arco Libros.

Margosein, C.M., Pascarella, E.T. y Pflaum, S.W. (1982). The effects of instruction using semantic mapping on vocabulary and comprehension. New York: Amaera.

Márquez Villegas, L. (1975). Vocabulario del español hablado. Madrid: SGEL.

Michéa, R., «Mots fréquents et mots disponibles; un aspect nouveau de la statistique du language», Les langues modernes, 1953, 47, págs. 338 344.

Morante, Roser (2005). El desarrollo del conocimiento léxico en segundas lenguas, Madrid: Arco/ Libros.

Nation, I. S. P. (2001). Learning vocabulary in another language. Victoria University of Wellington: Cambridge University Press.

Neggers, G. (1975). Cómo aumentar su vocabulario 2. Madrid: Playor.

Otaola Olano, C. (2004). Lexicología y semántica léxica. Madrid: Ediciones Académicas.

Penadés, I. (2004): "La enseñanza de la fraseología en el aula de ELE”, en Carabela 56, pp. 5168.

Picoche, J. (1993). Didactique du vocabulaire français. Paris: Nathan.

Rojo Sastre, A. J. (1980). Bases lexicológicas en una metodología audiovisual de la lengua española para extranjeros. Tesis Doctoral, Madrid: Universidad Complutense.

Salazar, V. / S. Pastor, eds. (2001). Tendencias y líneas de investigación en adquisición de segundas lenguas. Anexo 1. ELUA: Estudios de Lingüística de la Universidad de Alicante.

Sánchez Lobato, J. y Aguirre, B. (1992). Léxico fundamental del español. Madrid: SGEL.

Stark, M. (1990). Dictionary Workbooks. Exeter: University of Exeter Press.

Thornbury, S. (2002). How to teach vocabulary. Harlow: Longman.

Toms-Bronowski, s. (1971). An Investigation of the effectiveness of selected vocabulary teaching strategies with intermediate grade level students. University of Wisconsin at Madison, DAI, 1983, 44, 1405 .

Tréville, M.-C. / Duquette, L. (1996). Enseigner le vocabulaire en classe de langue. Vanves: Hachette. 